\title{
Traumatic brain injury in Uganda: exploring the use of a hospital based registry for measuring burden and outcomes
}

\author{
Amber Mehmood ${ }^{1}$, Nukhba Zia ${ }^{1 *}$, Connie Hoe ${ }^{1}$, Olive Kobusingye ${ }^{2}$, Hussein Ssenyojo $^{3}$ and Adnan A. Hyder
}

\begin{abstract}
Objective: Lack of data on traumatic brain injuries (TBI) hinders the appreciation of the true magnitude of the TBI burden. This paper describes a scientific approach for hospital based systematic data collection in a low-income country. The registry is based on the evaluation framework for injury surveillance systems which comprises a four-step approach: (1) identifying characteristics that assess a surveillance system, (2) review of the identified variables based on adopted specific, measurable, assignable, realistic, and time-related criteria, (3) assessment of the proposed variables and system characteristics by an expert panel, and (4) development and application of a rating system.

Results: The electronic hospital-based TBI registry is designed through a collaborative approach to capture comprehensive, yet context specific, information on each TBI case, from the time of injury until death or discharge from the hospital. It includes patients' demographics, pre-hospital and hospital assessment and care, TBI causes, injury severity, and patient outcomes. The registry in Uganda will open the opportunity to replicate the process in other similar context and contribute to a better understanding of TBI in these settings, and feed into the global agenda of reducing deaths and disabilities from TBI in low-and middle-income countries.
\end{abstract}

Keywords: Traumatic brain injuries, Registry, Uganda, Injury, Low-income country, Trauma, Surveillance

\section{Introduction}

Each year over 10 million people globally suffer traumatic brain injury (TBI) [1], which is a leading cause of brain disorders and disability worldwide. Road traffic injuries (RTI), which account for $60 \%$ of TBI cases, ranked as 8 th leading cause of death in 2015 (1.2 million deaths globally); an increase of about $19.7 \%$ since 1990 [2]. Other important contributors to TBI include falls $(20-30 \%)$, and violence $(10 \%)[2,3]$.

TBI incidence in sub-Saharan Africa $(150-170 / 100,000)$ is much higher than the global incidence $(106 / 100,000)$ [3]. Similarly, incidence of intracranial short-term injuries due to RTI and violence in sub-Saharan Africa are 1.47 and 3.34 times higher than global rates respectively.

\footnotetext{
*Correspondence: nukhba.zia@jhu.edu

1 Johns Hopkins International Injury Research Unit, Health Systems Program, Department of International Health, Johns Hopkins University Bloomberg School of Public Health, Baltimore, MD, USA

Full list of author information is available at the end of the article
}

Whereas incidence rates of intracranial long-term injuries due to war, violence and other unintentional injuries are 5.44, 3.37 and 1.86 times higher than their respective global incidence rates. Rapid motorization and conflicts have been attributed as important causes of the relatively higher TBI incidence in the region [4].

As with majority of sub-Saharan countries, data on the burden of injury and TBI in Uganda is scarce. According to a Ministry of Health report, the capital city Kampala had an estimated annual injury incidence of 116/1000, an injury mortality rate of $220 / 100,000$, an incidence of injury leading to disability of $23 / 1000$, and incidence of non-fatal injuries of 2.8/1000 [5]. Facility-based studies from Uganda estimated the cumulative incidence of TBI hospital admissions at $89 / 100,000$, with alarming figures for TBI-related mortality between 45.3 and 75\% [4, 6-8].

The number of deaths from RTI in Uganda has doubled from 3059 in 1990 to nearly 7800 in 2015 [2]. With a growth rate of $3.3 \%$, the population of the capital city Kampala, continues to rise, leading to greater numbers 
of vehicles and pedestrians on roads, and a resultant increase in road injuries and TBI incidence [9-11]. The day commuter population in Kampala is estimated at about 700,000 people, creating a risk pool of over 2 million people each day on the roads. As a result, approximately 9000 crashes are recorded each year in Kampala, which amounts to 25 crashes per day [12].

To better address the growing TBI burden, there are many critical gaps in knowledge that need to be addressed. Lack of good quality data on TBI hinders understanding of the magnitude of the burden and poses a barrier in identifying risks factors, vulnerable groups, and the impact of interventions. This issue was highlighted in a recent hospital-based study on severe TBI cases, that called for a need for systematic and efficient data collection that could have a positive impact on improving patient outcomes [4]. Thus, the overall goal of this paper is to introduce the development of an internet-based TBI registry in Uganda, based on an injury surveillance framework. The paper describes steps and components of the registry, Kampala internetbased Traumatic Brain Injury Registry (KiTBIR), which is the first of its kind in Uganda to understand the hospital-based TBI burden, risk factors in different populations and age groups, documentation of care processes, and indicators for quality of care. It is expected that the evidence generated from KiTBIR will facilitate the development of TBI management guidelines in resourceconstraint settings.

\section{Main text}

The registry development was guided by the core principles of injury surveillance, and hospital-based context. The evaluation framework for injury surveillance systems (EFISS) presented by Mitchell et al. [13] describes the scope of the surveillance system in a four-step approach: (1) identifying characteristics that assess a surveillance system, (2) a thorough review of identified characteristics/variables based on adapted specific measurable assignable realistic time-related (SMART) criteria, (3) assessment of the proposed variables and system characteristics by an expert panel, and (4) development and application of a rating system [13].

According to EFISS, injury surveillance system should be designed so that it could be evaluated for its data quality, operational characteristics, and practical considerations [13]. These attributes are summarized in Table 1. This paper focuses on the development and implementation of KiTBIR, where EFISS characteristics were adopted from the planning to the development phase of the registry, to be able to systematically monitor and evaluate specific attributes after implementation. Subsequent papers will discuss KiTBIR variables, results, sustainability and scale-up of the registry to other settings.

A multi-pronged approach was sought for finalizing the content and scope of KiTBIR. The approach involved a comprehensive literature review, identification of core variables, expert consensus meeting to shortlist the variables according to the scope and case definition. These steps are described in detail below:

The identification of potential variables in KiTBIR involved three strategies: (1) Literature review using search terms and MESH headings for "Brain injury AND Africa" and "Brain injury AND registry AND low-andmiddle-income countries (LMICs)". Several databases were searched using these terms including PubMed/ Medline, EMBASE, Scopus, Cochrane Reviews, System for Information on Grey Literature, and Global Health Ovid. The purpose of this review was to understand the published literature on characteristics and risk factors in the context of LMIC and sub-Saharan Africa between year 2006 and 2015 (Fig. 1). Twenty-four papers were selected and independently reviewed by two members of the research team. The result was development of a candidate list of TBI variables; (2) United States National Institute of Neurological Disorders and Stroke (NINDS) guidelines were reviewed for case definitions, TBI signs and symptoms; and (3) review of the previous work done by the team on development and implementation of injury surveillance tools and trauma registries $[14,15]$.

Core variables covered three main areas: risk factors, clinical care, and patient outcomes. These variables provide context-specific details of hospital burden of TBI, care processes and pre-hospital, emergency department (ED) and inpatient interventions. In addition, date/time variables for injury event, hospital presentation, triage and disposition were included to understand potential delays in care provision. Outcomes at discharge from the hospital was based on Glasgow Outcome Scale which has five categories; death, persistent vegetative state, severe disability, moderate disability and good recovery [16]. Scoring systems such as Kampala trauma score (KTS) was also proposed to measure the injury severity, and risk-adjusted outcome comparisons [17-19]. The final list of variables is available upon request.

The registry was envisioned to create a foundation for TBI prevention and improving quality of care by embedding indicators and outcomes for injury control, access to hospital care, care processes and outcomes. A multidisciplinary consensus meeting was held to finalize the scope of KiTBIR, core variables, data collection platform, and implementation process. The group consisted of local, regional and international public health practitioners, clinicians including neurosurgeons, injury prevention experts and information technology professionals. Time 


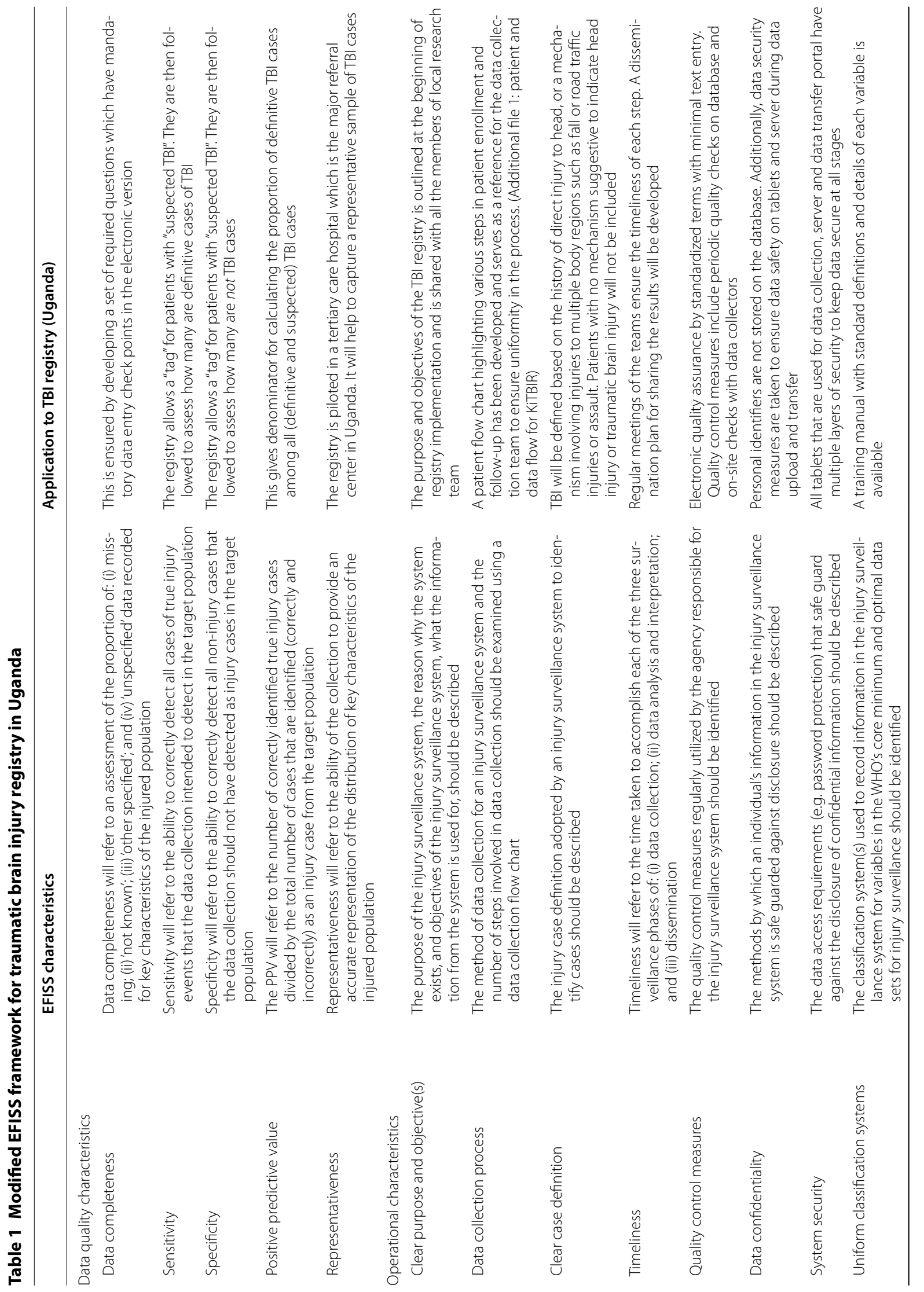




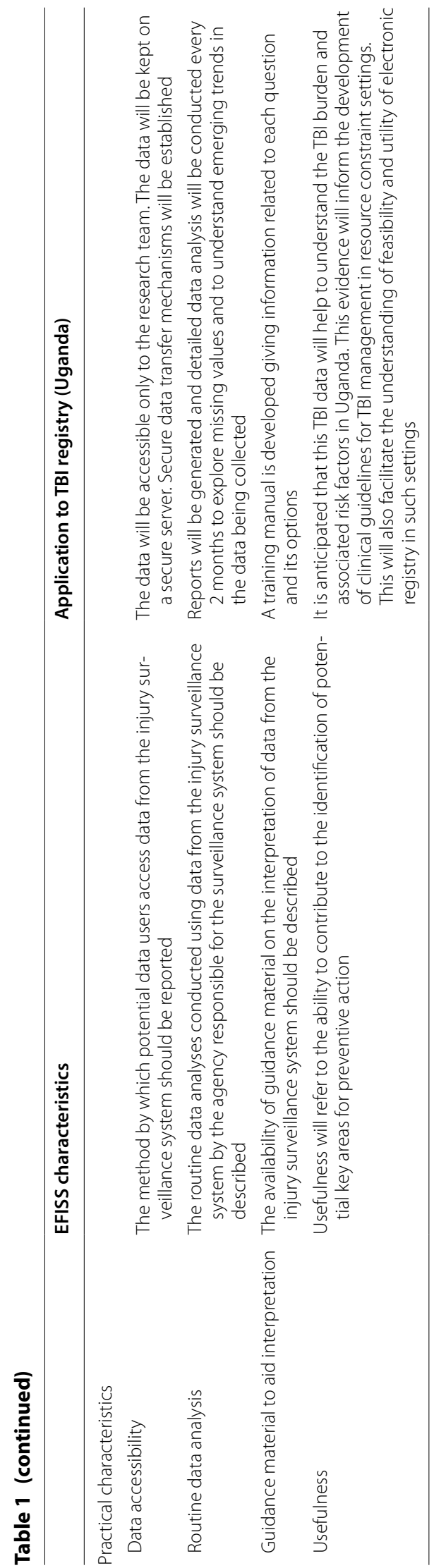




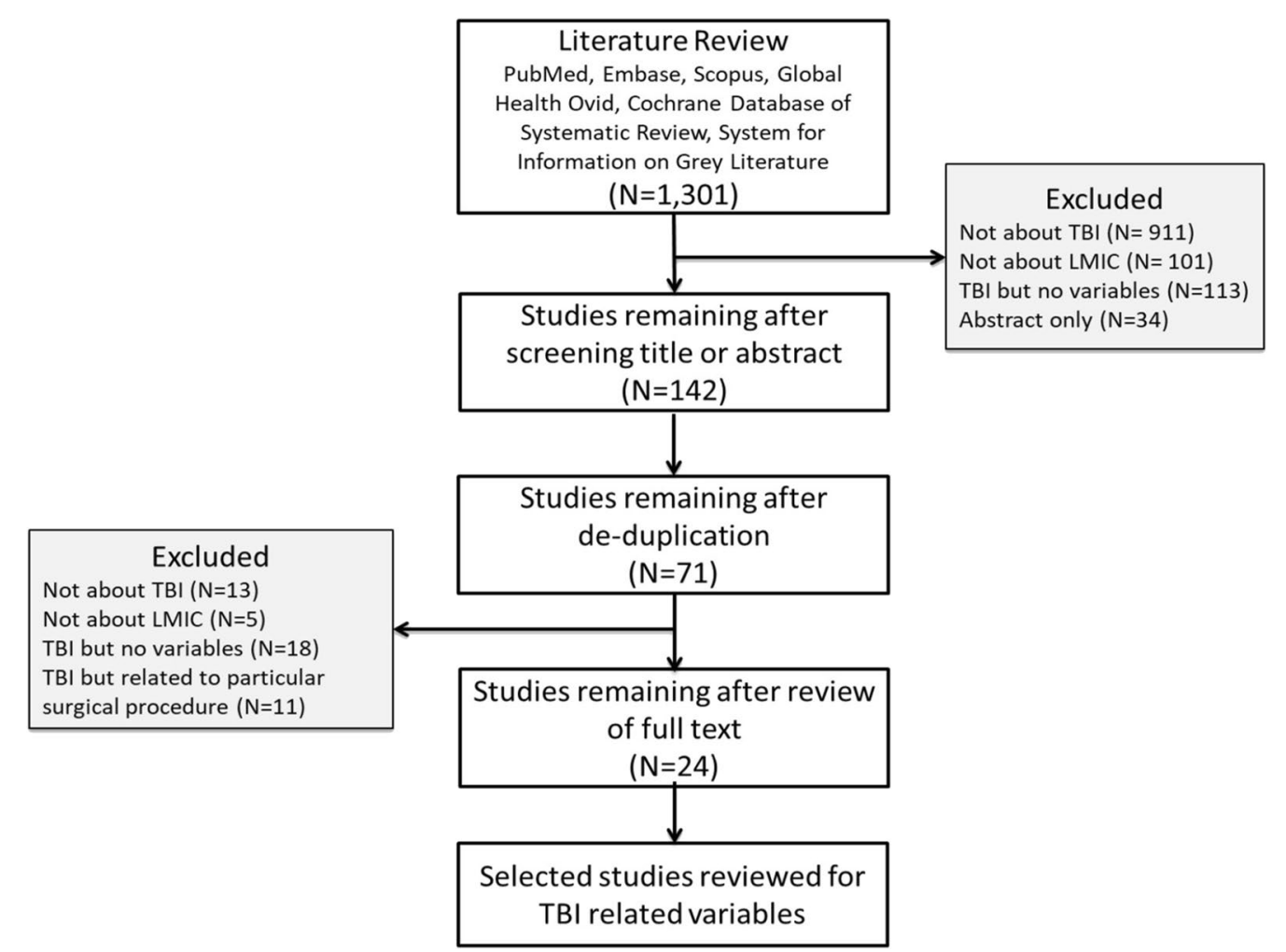

Fig. 1 Summary of literature review for identification of core variable for the traumatic brain injury registry

burden, local healthcare delivery processes, and data collection feasibility was also considered in finalization of the variables. Consensus was developed for the inclusion/exclusion criteria, operational definitions, and key performance indicators. Additionally, approaches to get reliable information, data collection procedures, training needs and ethical considerations were also established.

The final KiTBIR registry consists of six broad sections with 97 variables. Each section covers 5-29 questions, which are illustrated in Table 2 and include patients' demographics, pre-hospital and hospital assessment and care, external causes of injuries, injury severity measured by KTS and revised trauma score, and patient outcome. KiTBIR provides an opportunity for validation of KTS in TBI population of Uganda.

The registry was digitized using a m-health platform that was developed and pretested according to the local needs and resources available for TBI patients at the tertiary-care hospital in Kampala, Uganda.

In the digital platform, the flow of the information and organization of different sections was based on the usual course of patient in a tertiary-care hospital of Uganda (Additional file 1: Figure S1: patient and data flow for KiTBIR). Patients with TBI typically present to the ED where staff completes initial assessment to assess patient's condition and injuries, followed by specialty consultation based on the injury severity and need for hospital admission. Patients requiring inpatient admission are moved to neurosurgery ward while patients with less severe injuries are observed and discharged from ED. This patient flow is considered in designing the content and flow of questions in each section of KiTBIR to facilitate data collection.

Several steps were taken to develop a user-friendly and standardized data collection tool. OpenDataKit (https://opendatakit.org), an open source software for mobile data collection, was used and an Aggregate on a cloud server in Uganda was setup. Questionnaires were developed in Microsoft Excel XLSFORM, and uploaded to the Aggregate for data collection. The questionnaires largely consisted of dropdown menus and check boxes, along with mandatory fields such as age, sex, vital signs. The ODK-Collect app was downloaded on the Android tablets, secured through user-specific password, for data collection. Completed data collection forms on the tablet could be uploaded over Wi-Fi or internet connection to the Aggregate on the cloud server. Data quality control measures, confidentiality, and system security were in place. The encryption of the device was supported by elliptic curve cryptography and script; this provided 
Table 2 Sections and variables in KiTBIR

\begin{tabular}{|c|c|c|}
\hline Sections/domains & Sample variables & References $^{\mathbf{a}}$ \\
\hline 1. Patient demographic information & $\begin{array}{l}\text { Age, sex, area of residence, marital status, highest education, employment } \\
\text { status }\end{array}$ & {$[4,23-43]$} \\
\hline 2. Pre-hospital care & $\begin{array}{l}\text { Care details included first aid and pre-hospital assessment, transport time, } \\
\text { mode of arrival }\end{array}$ & {$[25,29,37,39,40]$} \\
\hline 3. Injury event information & Date and time of injury, place and activity of injury & {$[4,23-26,28-43]$} \\
\hline 4. Emergency room assessment and treatment & $\begin{array}{l}\text { Vital signs, GCS, pre-existing conditions, suspicion of alcohol and substance } \\
\text { use, lab and radiology investigations, patient management, respiratory } \\
\text { support, ED disposition }\end{array}$ & {$[4,23,25-37,39,41]$} \\
\hline 5. Inpatient care & Surgical treatment, complications, ICU care & {$[23-25,32,34,37,39,42]$} \\
\hline 6. Discharge & Discharge outcome, length of stay & {$[4,23-32,34-46]$} \\
\hline Quality indicators & $\begin{array}{l}\text { Duration between injury and arrival, time seen by neurosurgical team, date } \\
\text { and time of intubation, ED length of stay, date and time of CT and surgical } \\
\text { intervention }\end{array}$ & \\
\hline Injury and outcome measures & $\begin{array}{l}\text { Revised trauma score, Kampala score, Glasgow outcome score; pre- and } \\
\text { post-resuscitation GCS }\end{array}$ & \\
\hline
\end{tabular}

a Studies that mentioned the listed variables selected for KiTBIR

additional security of the data with the ability to remotely activate android device manager to lock or erase information in case of stolen or lost device.

\section{Strengths and limitations}

This is one of the first studies designed to collect prospective hospital-based data on TBI patients in a large tertiary-care hospital of a low-income setting, employing electronic data collection methods. KiTBIR demonstrated several advantages: First, it feeds into a surveillance system, documents the hospital-based TBI burden, risk factors, injury mechanisms, outcomes, allows to fill information gaps on the vulnerable populations, and develop strategies for prevention and control [20].

Second, KiTBIR documents care processes and performance indicators in a low-resource setting, that functions with limited infrastructure, human resources, access to care, and efficiency compared to high-income countries [21]. Combining core surveillance measures with hospital-based care processes and outcome, makes KiTBIR a robust tool to perform dual function of surveillance and monitoring quality of care. Development and implementation of clinical management protocols and data-driven policies to improve outcomes of TBI patients in Uganda will be the ultimate impact of the registry.

Third, this hand-held based data collection tool uses innovative approach which could become a foundation for multicenter injury database [22]. Using open-source software and smart electronic devices is the way forward to streamlining data collection in setups lacking electronic medical record systems. The collaborative approach has resulted in understanding local context and developed local capacity for future sustainability and integration of the registry into the current system at the hospital.

Lastly, utilization of the EFISS framework provided the basis of the planning and development of KiTBIR, and ensured that data quality, operational challenges and practical considerations were taken into account. Similar approaches could guide other researchers and clinicians in development of a comprehensive database for injury surveillance and hospital-based registries. The planning and implementation of KiTBIR, based on EFISS provides a proof of concept that low-cost, good quality, reliable injury surveillance systems could be established and help identify targeted strategies to increase the uptake of the system and expand it to other clinical settings.

There are some limitations of this work. First, KiTBIR is designed to collect data on TBI patients from their point of entry to exit from the hospital. In a resourcelimited tertiary care setting, tracking patients through their entire course, especially those involving multiple departments and locations, might present a unique challenge. There is lack of centralized information system to update patients' location or discharge in real time, and this could potentially result in missing information, or loss of patient follow-up after leaving ED.

Second, since this is the first time that tablets are used for data collection in the hospital, there is a risk of loss of data in case of tablet malfunction, theft, etc., if not timely uploaded on the servers. In such instances, the data will not be retrievable. During implementation phase, effort would be made to ensure data submission within $24 \mathrm{~h}$ of patient presentation to the ED.

A customized electronic TBI registry will open opportunity to replicate the process in similar settings 
and contribute to the global agenda of reducing deaths and disabilities from TBI in low-income countries.

\section{Additional file}

Additional file 1. Patient and data flow for KiTBIR.

\section{Abbreviations}

EFISS: evaluation framework for injury surveillance systems; KiTBIR: Kampala internet-based Traumatic Brain Injury Registry; LIC: low-income countries; LMIC: low-and-middle income country; RTI: road traffic injury; SMART: specific measurable assignable realistic time; TBI: traumatic brain injuries; WHO: World Health Organization.

\section{Authors' contributions}

$\mathrm{AM}, \mathrm{NZ}, \mathrm{CH}, \mathrm{OK}, \mathrm{HS}$ and $\mathrm{AAH}$ were involved in the conception and design of the tool and the study. All authors revised the article critically for important intellectual content. All authors read and approved the final manuscript.

\section{Author details}

1 Johns Hopkins International Injury Research Unit, Health Systems Program, Department of International Health, Johns Hopkins University Bloomberg School of Public Health, Baltimore, MD, USA. ${ }^{2}$ Makerere University's School of Public Health, Kampala, Uganda. ${ }^{3}$ Department of Neurosurgery, Mulago Hospital, Kampala, Uganda.

\section{Acknowledgements \\ Not applicable.}

\section{Competing interests}

The authors declare that they have no competing interests.

\section{Availability of data and materials}

Data sharing is not applicable to this article as no datasets were generated or analyzed during the current study.

\section{Consent for publication}

Not applicable.

\section{Ethics approval and consent to participate}

Ethical review and approval for this study is taken from the Institutional Review Boards (IRB) of the Johns Hopkins School of Public Health, Makerere University School of Public Health and Uganda National Council. Oral consent will be taken from study participants and will be informed during the consent process that their data will be de-identified and aggregated data will be published in scientific journal and disseminated through community awareness programs. Oral consent is considered instead of written consent to include individuals who are not educated and therefore, unable to read and write. This is mentioned in the IRB applications and is approved by all the three IRBS mentioned above. The data collection of this project is completed and results will be shared in future publications.

\section{Funding}

This study was supported by Grant (R21NS085094) to Johns Hopkins University under the Global Brain Disorders Research award of the Fogarty International Center at the US National Institutes of Health (NIH). The funding agency had no role in study design, data collection, data analysis, data interpretation, or decision to submit this manuscript for publication. The corresponding author had full access to all the data in the study, and had final responsibility for the decision to submit for publication.

\section{Publisher's Note}

Springer Nature remains neutral with regard to jurisdictional claims in published maps and institutional affiliations.

Received: 26 February 2018 Accepted: 9 May 2018

Published online: 15 May 2018
References

1. World Health Organization. Neurological disorders: public health challenges. Geneva: World Health Organization; 2006.

2. The Global Burden of Disease Study 2015 University of Washington. Seattle: Institute for Health Metrics and Evaluation; 2016. http://www. healthdata.org/gbd. Accessed 30 Jan 2017

3. Hyder AA, Wunderlich CA, Puvanachandra P, et al. The impact of traumatic brain injuries: a global perspective. NeuroRehabilitation. 2007:22(5):341-53.

4. Tran TM, Fuller AT, Kiryabwire J, et al. Distribution and characteristics of severe traumatic brain injury at Mulago National Referral Hospital in Uganda. World Neurosurg. 2015;83(3):269-77.

5. Uganda Ministry of Health. Health management information system report. Kampala: Ministry of Health; 2000.

6. Hsia RY, Ozgediz D, Mutto M, et al. Epidemiology of injuries presenting to the national hospital in Kampala, Uganda: implications for research and policy. Int J Emerg Med. 2010;3(3):165-72.

7. Jayaraman S, Ozgediz D, Miyamoto J, et al. Disparities in injury mortality between Uganda and the United States: comparative analysis of a neglected disease. World J Surg. 2011;35(3):505-11.

8. Kwizera A, Dunser M, Nakibuuka J. National intensive care unit bed capacity and ICU patient characteristics in a low income country. BMC Res Notes. 2012;5:475

9. Uganda Bureau of Statistics. Uganda population and housing census analytical report: education and literacy. Kampala: Uganda Bureau of Statistics; 2006

10. The World Bank Data. Washington DC: The World Bank; 2016.

11. National Population and Housing Census-provisional results. Kampala: Uganda Bureau of Statistic; 2014. http://unstats.un.org/ unsd/demographic/sources/census/wphc/Uganda/UGA-2014-11.pdf. Accessed 1 Aug 2017.

12. Nasasira JH. Call for a decade of action for road safety CALL: launch of the second report of the commission for global road safety. Kampala: Uganda Ministry of Works and Transport; 2009.

13. Mitchell RJ, Williamson AM, O'Connor R. The development of an evaluation framework for injury surveillance systems. BMC Public Health. 2009;9:260

14. Mehmood A, Razzak JA, Kabir S, et al. Development and pilot implementation of a locally developed trauma registry: lessons learnt in a low-income country. BMC Emerg Med. 2013;13:4.

15. Mehmood A, Allen KA, Al-Maniri A, et al. Trauma care in Oman: a call for action. Surgery. 2017:162:S107.

16. McMillan TM, Weir CJ, Ireland A, et al. The glasgow outcome at discharge scale: an inpatient assessment of disability after brain injury. J Neurotrauma. 2013;30(11):970-4.

17. Kobusingye OC, Lett RR. Hospital-based trauma registries in Uganda. J Trauma. 2000;48(3):498-502.

18. Hung YW, He H, Mehmood A, et al. Exploring injury severity measures and in-hospital mortality: a multi-hospital study in Kenya. Injury. 2017;48:2112-8.

19. Weeks SR, Juillard CJ, Monono ME, et al. Is the Kampala trauma score an effective predictor of mortality in low-resource settings? A comparison of multiple trauma severity scores. World J Surg. 2014;38(8):1905-11.

20. Krug EG. Injury surveillance is key to preventing injuries. Lancet. 2004;364(9445):1563-6.

21. Gruen RL, Gabbe BJ, Stelfox HT, et al. Indicators of the quality of trauma care and the performance of trauma systems. Br J Surg. 2012;99(Suppl 1):97-104.

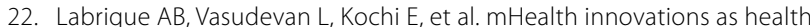
system strengthening tools: 12 common applications and a visual framework. Global Health Sci Pract. 2013:1(2):160-71.

23. du Toit-Prinsloo L, Saayman G. Fatal head injuries in children under the age of 5 years in Pretoria. Am J Forensic Med Pathol. 2014:35(3):212-7.

24. Maier D, Njoku I Jr, Schmutzhard E, et al. Traumatic brain injury in a rural and an urban Tanzanian hospital-a comparative, retrospective analysis based on computed tomography. World Neurosurg. 2014;81(3-4):478-82.

25. Kiboi JG, Kitunguu PK, Angwenyi P, et al. Predictors of functional recovery in African patients with traumatic intracranial hematomas. World Neurosurg. 2011;75(5-6):586-91. 
26. Hassan NA, Kelany RS, Emara AM, et al. Pattern of craniofacial injuries in patients admitted to Tanta University Hospital-Egypt. J Forensic Leg Med. 2010;17(1):26-32.

27. Zulu BM, Mulaudzi TV, Madiba TE, et al. Outcome of head injuries in general surgical units with an off-site neurosurgical service. Injury. 2007;38(5):576-83.

28. Qureshi JS, Ohm R, Rajala H, et al. Head injury triage in a sub Saharan African urban population. Int J Surg. 2013;11(3):265-9.

29. Nnadi MON, Bankole OB. Traumatic brain injury patients: direct versus inter-facility transfer time to neurosurgical center and the effects on outcome. East Central Afr J Surg. 2014;19(2):59-65.

30. Winkler AS, Tluway A, Slottje D, et al. The pattern of neurosurgical disorders in rural northern Tanzania: a prospective hospital-based study. World Neurosurg. 2010;73(4):264-9.

31. Hitimana J, Perez M, Kinasha A, et al. Clinical presentation and outcome of neurosurgical conditions at Butare Teaching Hospital, Rwanda. East Central Afr J Surg. 2009;14(1):50-6

32. Kesinger MR, Nagy LR, Sequeira DJ, et al. A standardized trauma care protocol decreased in-hospital mortality of patients with severe traumatic brain injury at a teaching hospital in a middle-income country. Injury. 2014;45(9):1350-4.

33. Bahloul M, Chelly H, Ben Hmida M, et al. Prognosis of traumatic head injury in South Tunisia: a multivariate analysis of 437 cases. J Trauma. 2004;57(2):255-61.

34. Imen RB, Olfa C, Kamilia C, et al. Factors predicting early outcome in ptients admitted at emergency department with head trauma. J Acute Dis. 2015;4(1):68-72.

35. Morisse E, Favarel-Garrigues JF, Couadau E, et al. Incidence of hospitaladmitted severe traumatic brain injury and in-hospital fatality rates in a Pacific Island country: a 5-year retrospective study. Brain Inj. 2014;28(11):1436-40.
36. Wu X, Hu J, Zhuo L, et al. Epidemiology of traumatic brain injury in eastern China, 2004: a prospective large case study. J Trauma. 2008;64(5):1313-9.

37. Chalya PL, Kanumba ES, Mabula JB, et al. Aetiological spectrum, injury characteristics and treatment outcome of head injury patients at Bugando Medical Centre in north-western Tanzania. Tanzania J Health Res. 2011;13(1):74-81.

38. Idowu OE, Akinbo O. Neurotrauma burden in a tropical urban conurbation level I trauma centre. Injury. 2014;45(11):1717-21.

39. Bahloul M, Ben Hamida C, Chelly H, et al. Severe head injury among children: prognostic factors and outcome. Injury. 2009;40(5):535-40.

40. Adeolu AA, Abiona TC, Komolafe EO, et al. Epidemiology of neurotrauma in Ife-ljesha zone of Nigeria. World Neurosurg. 2013;80(3-4):251-4.

41. Okyere-Dede EK, Nkalakata MC, Nkomo T, et al. Paediatric head injuries in the Kwazulu-Natal Province of South Africa: a developing country perspective. Trop Doct. 2013;43(1):1-4.

42. Dias C, Rocha J, Pereira E, et al. Traumatic brain injury in Portugal: trends in hospital admissions from 2000 to 2010. Acta Med Port. 2014;27(3):349-56.

43. Shao J, Zhu H, Yao H, et al. Characteristics and trends of pediatric traumatic brain injuries treated at a large pediatric medical center in China, 2002-2011. PLOS ONE. 2012;7(12):e51634.

44. Adeleye AO, Olowookere KG, Olayemi OO. Clinicoepidemiological profiles and outcomes during first hospital admission of head injury patients in Ikeja, Nigeria. A prospective cohort study. Neuroepidemiology. 2009;32(2):136-41.

45. Klimo P Jr, Ragel BT, Jones GM, et al. Severe pediatric head injury during the Iraq and Afghanistan conflicts. Neurosurgery. 2015;77(1):1-7 (discussion)

46. Udoh DO, Adeyemo AA. Traumatic brain injuries in children: a hospitalbased study in Nigeria. Afr J Paediatr Surg. 2013;10(2):154-9.
Ready to submit your research? Choose BMC and benefit from:

- fast, convenient online submission

- thorough peer review by experienced researchers in your field

- rapid publication on acceptance

- support for research data, including large and complex data types

- gold Open Access which fosters wider collaboration and increased citations

- maximum visibility for your research: over 100M website views per year

At $\mathrm{BMC}$, research is always in progress.

Learn more biomedcentral.com/submissions 